\title{
TRÂNSITO DE TEMAS COMUNS ENTRE O JN E AS TELENOVELAS
}

\author{
TRANSIT OF COMMON THEMES BETWEEN \\ THE JN AND SOAP OPERAS
}

\begin{abstract}
GUILHERME JORGE DE REZENDE
Bacharel em Comunicação pela UFMG, Mestre em Ciências da Comunicação pela ECA/USP e Doutor em Comunicação pela UMESP. Professor Associado II na Universidade Federal de São João del-Rei, é professor da graduação em Letras e do Mestrado em Crítica da Cultura. Coordenador do Curso de Comunicação Social, habilitação jornalismo, em fase de implantação na UFSJ.
\end{abstract}

\section{RESUMO}

Este artigo trata da incidência do sincretismo da realidade-ficção na televisão brasileira. A investigação parte da hipótese de que a interpenetração desses gêneros de programas se explicita no trânsito de conteúdos entre o telejornal e as telenovelas, mediante um espetáculo contínuo. O corpus do estudo compreendeu a sequência de programas exibidos em janeiro de 2000, pela Rede Globo de Televisão, na qual o Jornal Nacional se inseria entre duas telenovelas, "Vila Madalena" e "Terra Nostra". A pesquisa revelou indícios de uma notável recorrência de temas e abordagens na programação do horário nobre da emissora de maior audiência no Brasil.

Palavras-chave: Sincretismo da realidade-ficção, Rede Globo de Televisão, Jornal Nacional, Vila Madalena, Terra Nostra.

\section{ABSTRACT}

This article deals with the incidence of the reality-fiction syncretism in the Brazilian television. The investigation begins with the hypothesis that the interpenetration of these sorts of programs occurs in between the television news and the soap-opera contents, by means of a continuous spectacle. The corpus of the study has included the series of programs shown in January of 2000, by Rede Globo de Televisão, in which Jornal Nacional was inserted between two soap-operas, Vila Madalena and Terra Nostra. The research disclosed evidences of a notable recurrence of subjects and approaches in the schedule of the major Brazilian network prime time.

Keywords: Reality-fiction syncretism, Brazilian television, Rede Globo de Televisão, Jornal Nacional, Vila Madalena, Terra Nostra. 
Em 2000, realizei uma pesquisa sobre a incidência da realidade-ficção na televisão brasileira. Tive a colaboração de dois bolsistas de iniciação científica do PIBIC/FUNREI/CNPq. Um deles, Wagner Teixeira Dias, concentrou sua investigação em duas telenovelas da Rede Globo de Televisão, "Vila Madalena" e "Terra Nostra". A outra bolsista, Patrícia Alves Dias, se dedicou ao estudo de edições do "Jornal Nacional", no mesmo período.

A investigação partiu da hipótese de que, com uma frequência considerável, conteúdos se interpenetravam nos dois gêneros de programas, não por coincidência, mas como explicitação de um espetáculo contínuo para atrair a atenção do telespectador.

Este artigo relata alguns resultados da análise do conteúdo das telenovelas e do telejornal. As evidências observadas apontam indícios de uma notável recorrência de temas e abordagens no horário nobre da tevê brasileira.

\section{Realidade e ficção no horário nobre}

A intercalação de "um telejornal - o Jornal Nacional - entre duas telenovelas, as conhecidas e denominadas novela das sete e novela das oito" condiciona uma rotina no comportamento da audiência, no prime time da grade horária da TV Globo. Criou-se "o hábito de ver TV, em família, com programação e horários reforçando-se mutuamente e garantindo uma fidelidade de público e um aumento vertiginoso dos índices de audiência [...]" (BORELLI; PRIOLLI, 2000, p. 19).
Essa tendência se enraizou tão intensamente que o ensaísta Nélson Archer chegou a questionar se o fenômeno não seria de fato uma peculiaridade essencial da linguagem televisiva.

\section{[...] os limites entre realidade $e$ ficção, assim como a natureza de ambas, estão sendo negociados e renegociados ininterruptamen- te, diante dos nossos olhos, nas telas de milhões de televisores. Será que é muito despropositado afirmar que, se a TV tenha al- guma função, seja precisamente esta? (ASCHER, 2001).}

Estratégia já utilizada na imprensa europeia do século XIX - em que Jornalismo e melodrama mantinham uma convivência íntima (MEYER, 1996), a afinidade entre realidade e ficção ganha ênfase no texto clássico de Adorno e Horkheimer sobre a Indústria Cultural. Referindo-se às produções cinematográficas, os pensadores da Escola de Frankfurt argumentavam que "o mundo da rua é o prolongamento do espetáculo encenado no cinema", para ressaltarem que "a vida não deve mais poder se distinguir do filme" (ADORNO; HORKHEIMER, 1978, p. 165)

Edgar Morin retomou essa questão em outra conjuntura, onde a TV assumia uma posição de destaque entre os mass media, para enfatizar que "a cultura de massa é animada por esse duplo movimento do imaginário arremedando o real e do real pegando as cores do imaginário (MORIN, 1967, p. 39) .

Em sintonia com Morin, Martin-Barbero afirma que o folhetim seria a ponte para a inclusão 
do romance escrito na imprensa. "A indústria cultural produz uma informação onde primam os "sucessos", isto é, o lado extraordinário e enigmático da atualidade cotidiana, e uma ficção na qual predominará o realismo." (MARTIN-BARBERO, 1997, p. 82)

$\mathrm{Na}$ década de 1980, Umberto Eco esclareceu que na Neotevê, "não se está mais em questão [...] a aderência entre o enunciado e o fato, mas a verdade da enunciação que diz respeito à cota de realidade daquilo que aconteceu no vídeo" e não do que "foi dito através do vídeo" (ECO, 1984, p.188).

Essa mistura de realidade e ficção não foi sempre assim tão intensa. Se "nos primórdios da televisão, havia uma clara separação entre o mundo do espetáculo, da encenação, da fantasia e o mundo da vida prática, cotidiana", a evolução tecnológica tornou-a cada vez mais tênue: "Os fatos do mundo [...] passaram a ser narrados como telenovela, e a telenovela adquiriu o estatuto de um fato do mundo" (ARBEX, 1996, p. 23-24).

Outro autor brasileiro reforça essa impressão, assinalando que o telejornalismo, revela um "novo horizonte informativo, em que a informação pura e simples já não é tão importante, mas é a encenação da informação que toma o lugar principal" (MARCONDES FILHO, 1994, p. 45).

\section{Fait divers ou fatos-ônibus}

No jornalismo, o sincretismo da realidade-ficção tem a fisionomia do fait divers, informação cujo conteúdo "não é estranho ao mundo: desastres, raptos, agressões, acidentes, roubos, esquisitices, tudo isso remete ao homem, à sua história, à sua alienação, a seus fantasmas, a seus sonhos, a seus medos" (BARTHES, 1970, p. 58).

Pierre Bourdieu (1997) indicou outra expressão - informação-ônibus - para denominar o mesmo fenômeno de dissimulação do real.

As notícias de variedades consistem nessa espécie elementar, rudimentar da informação que é muito importante porque interessa a todo mundo sem ter conseqüências e porque ocupa tempo que poderia ser empregado para dizer outra coisa [...] o tempo que é extremamente raro na televisão. E se esses minutos tão preciosos são empregados para dizer coisas tão fúteis são de fato muito importantes na medida em que ocultam coisas preciosas (BOURDIEU, 1997, p. 23).

A prática de exibir reconstituições que se enquadram no conceito de fait divers, segundo Jespers, acentua a impressão do sincretismo da realidade-ficção, porque "o espectador corre o risco de não fazer a distinção entre folhetim e a informação, entre a ficção e a representação jornalística da realidade" (JESPERS, 1998, p. 61).

Como efeito desse processo, "a tela da TV torna a realidade simulacro". As imagens adquirem tal grau de auto-suficiência que se impõem ao que de fato se passa no "mundo real", criando-se "espetáculos dramatizados, nos quais a informação ocupa um espaço secundário" (TEMER; TONDATO, 2009, p.17). 
Por essa razão, o telejornalismo no Brasil "se organiza como melodrama" para, através da oferta do espetáculo "como se fossem produtos de puro entretenimento" criar "um vínculo afetivo" (BUCCI, 1996: 26) com o telespectador. Nessa condição de melodrama, "o telejornalismo, de modo destacado o Jornal $\mathrm{Na}$ cional, passou a seguir algumas regras próprias do melodrama, em suas edições diárias. A regra central é o permanente conflito entre o bem e o mal, que culmina no "boa-noite, com um happy end de preferência. Em cada bloco, ou a cada dois blocos, o bem vence o mal (ou no mínimo tenta vencê-lo)" (BUCCI, 1996, p. 31).

François Jost assinala que o telejornal, "embora pretenda falar da realidade, observa-se frequentemente que ele a reduziu ao visível, a ponto de, às vezes, a existência dos acontecimentos depender de sua capacidade de visualização" (JOST, 2004, p. 84). Essa supervalorização da imagem do fato, de modo a tornar a representação mais crível do que o fato por si mesmo, é um dos fundamentos da crítica de Debord (1997) à Sociedade do Espetáculo.

A mesma lógica poderia justificar também a escolha dos apresentadores do Jornal Nacional, William Bonner e Fátima Bernardes, par romântico idealizado - jovens, bonitos, bem sucedidos - semelhantes aos casais de personagens das telenovelas?

Para Sean Hagen (2005), o sentido da presença do casal na bancada do telejornal ultrapassa os limites do campo meramente informativo: os dois apresentadores "circulam entre dois mun- dos", o das pessoas comuns e o das celebridades, representando, ao mesmo tempo, o discurso da imparcialidade, objetividade do universo jornalístico televisivo e todo o glamour próprio das vedetes da indústria cultural (HAGEN, 2005, p.103).

Entre as pesquisas realizadas sobre o sincretismo da realidadeficção no telejornalismo brasileiro, sobressai o estudo de Iluska Coutinho acerca da estrutura dramática nos telejornais. Uma das características que verificou foi "a presença da marca melodramática no horário nobre global em $11,76 \%$ das matérias apresentadas pelo JN" (COUTINHO, 2006 , p. 118) na semana de edições que analisou.

\section{O sincretismo no melodrama realista}

Correspondente nas telenovelas do fait divers, o melodrama é a mais eloquente expressão do sincretismo da cultura popular e de massa na América Latina. Ambientada em cenários do cotidiano familiar, a trama melodramática na telenovela contém todos os ingredientes do espetáculo televisivo. (BALOGH, 2002) e a catarse maciça e descargas emocionais que oferece a qualquer tipo de público organizam a compreensão da realidade" (Carlos Monsivais Apud. MATTELART \& MATTELART, 1989, p. 19),

Em seus primeiros anos, a telenovela brasileira repetiu um modelo melodramático latinoamericano. A partir dos anos 60, depois do endurecimento do regime militar, dramaturgos de grande talento, como Dias Gomes e 
Lauro César Muniz, encontram na telenovela uma alternativa para driblar a censura, e expor suas críticas sociais. Começa-se, então, a se "abrir caminho para uma estética que gira como um cata-vento maluco entre a ficção e a realidade" (FAERMAN, 1998, p. 79).

Foi, porém, com Beto Rockfeller, de Bráulio Pedroso, em 1968-1969, na TV Tupi, que se consolidou o "gênero romântico-realista, mesclando folhetim tradicional com esboços de dramaturgia popular, nacional, em íntima conexão com aspirações do mercado: a mistura do mito de Cinderela com sociologia" (TÁVOLA, 1996, p. 94).

Pode-se dizer que, desde então, ao promover um desenvolvimento paralelo de "histórias de amor" (romantismo) e "temáticas sociais (realismo)", a telenovela se transforma em um espaço cultural em que cotidianos do real e do imaginário interagem.

Clarice Herzog afirma que o impacto da telenovela no dia-adia de grande parte da população brasileira se amplia ao marcar

[...] a rotina da família e serve como ponto de referência para as atividades do cotidiano. Ela regula o ritmo da vida, os horários, os afazeres, não apenas os da casa como os pessoais (...). Grande parte da ordem dos dias é determinada pela novela: o fim do dia, o fim da semana... o início da semana, o próximo capítulo, o próximo dia [...] (HERZOG, 1997, p. 49).

A telenovela motiva o telespectador a se relacionar com os personagens dessa trama ficcional, porque "preenche o cotidiano das pessoas (...) de forma mais rica, densa e emocionante do que a própria vida." E substitui um convívio social que por uma série de fatores já não se dá mais (...) através de um componente de familiaridade do dia a dia telenovelístico que garante e facilita a aceitação das pessoas" (MARCONDES FILHO, 1994, p. 45).

Nesse estilo peculiarmente brasileiro de produzir telenovela, o realismo superpõe-se ao romantismo. Por meio de uma estética "naturalista", dota-se a narrativa melodramática de um teor realista, que permite a telenovela "acompanhar jornalisticamente as transformações afetivas na família liberal-burguesa, incorporando pelos roteiros dramáticos temas como liberdade sexual, juvenilização dos velhos, descasamentos e muitos outros afins à crítica dos costumes" (SODRÉ, 1991, p. 227).

Em análise sobre as representações verossímeis da contemporaneidade apresentadas na TV, Esther Hamburger identifica relações "da ficção e da notícia" nas telenovelas "Irmãos Coragem", "Roque Santeiro", "Selva de Pedra" e "Vale Tudo" (HAMBURGER, 2003). A verossimilhança do universo ficcional das novelas é construída da apropriação recorrente de elementos da linguagem jornalística para aludir a eventos da conjuntura, elementos da cultura e da história do Brasil (HAMBURGER, 2003, p. 142).

Mauro Wilton adverte, no entanto, que há que se ter em conta o limite de eficácia dessa fusão das duas instâncias: "na hora que a telenovela é só reportagem, é 
recusada pelo público. $\mathrm{Na}$ hora em que é só ficção, não atrai, não tem poder de sedução" (Apud FAERMAN, 1998, p. 80).

O que parece inquestionável mesmo é a conveniência do sincretismo na telenovela. Para Maria Aparecida Baccega, a permanente troca entre a ficção e a realidade, "não descreve a própria realidade, mas faz as pessoas verem, a partir da emoção, algumas questões da realidade" (Apud FAERMAN, 1998, p. 82).

Não só os teóricos defendem essa prática. A autora de telenovelas Glória Perez considera o seu ofício uma oportunidade de viver o cotidiano das pessoas comuns. Consciente da existência do sincretismo, ela propõe que o jornalismo deve ficar atrelado à ficção nas telenovelas, as quais, sem perder a condição de diversão, podem "cumprir também uma função, promovendo debates e colocando questões" (NEPOMUCENO, 1998, p. 96).

\section{O trânsito de temas no estudo empírico}

O primeiro procedimento metodológico, o estudo empírico, consistiu na gravação integral de sete edições do telejornal e dos capítulos das duas telenovelas, correspondentes ao período do dia 10 de janeiro a 17 de janeiro do ano 2000. O passo seguinte foi a identificação de temas e abordagens comuns aos dois gêneros de programas. Para este artigo, foram selecionados três temas recorrentes: a criança e a juventude, a violência e a mobilidade. Outras questões como o amor, o sexo, a liberda- de e a iniciativa privada, permearam as referências a esses temas selecionados.

\section{Exaltação da criança e dos valores juvenis}

A criança e os valores juvenis foram temas bastante focalizados no JN. No total, dezoito minutos e seis segundos das seis edições semanais do telejornal foram destinados às notícias envolvendo crianças.

Relevância similar atribuiu-se a essa temática nas duas telenovelas. Assim como na vida real, as crianças de "Vila Madalena" e "Terra Nostra" foram vítimas de desentendimentos dos adultos, principalmente de seus pais.

Especificamente em "Vila Madalena", observou-se que os filhos de Eugênia (Maitê Proença) e Arthur (Herson Capri) sofriam por causa do destino incerto: ora viviam com o pai, ora com a mãe. O pai não lhes oferecia o carinho, a compreensão e o respeito de que elas precisavam. O dinheiro de Arthur era usado como instrumento de manipulação das crianças, a ponto de leválas a sentirem aversão pela mãe.

Em "Terra Nostra", os fatos eram ainda mais complicados. Giuliana (Ana Paula Arósio) e Mateo (Thiago Lacerda), após um intenso romance na viagem de imigração para o Brasil, acabaram se separando quando chegaram a São Paulo. Para aumentar o teor dramático, Giuliana, depois de ter filho sozinha, foi alvo da crueldade da dona da casa onde estava hospedada, Madame Janete (Ângela Vieira), que ordena à sua governanta a levar 
o bebê para a roda dos excluidos.

Já casada com Marco Antônio (Marcelo Anthony), Giuliana (Ana Paula Arósio) dá à luz a outra criança. No entanto, o casal, que se unira por conveniência, se separa, originando mais uma tragédia infantil, ao privar a criança até mesmo da amamentação pela mãe.

Outro personagem infantojuvenil, o menino negro Tizil (André Luiz), sonha com o dia em que poderá sentar-se em uma cadeira de escola. Filho de ex-escravos, se vê obrigado a trabalhar como engraxate nas ruas de São Paulo. Contudo, em consonância com o slogan "Toda criança na escola", em que a Rede Globo relevava seu compromisso com a educação, Tizil consegue ser matriculado e troca a função de engraxate por um trabalho digno, na casa bancária ítalo-brasileira de Francesco (Raul Cortez), que não o impediria de estudar.

Muito além de uma mera coincidência, o Jornal Nacional dedicou parte significativa de seu noticiário a matérias a respeito da realidade infantil. Em uma delas, a notícia sobre engraxates brasileiros que construíram uma carreira promissora em Nova Iorque, é uma referência explícita ao menino Tizil, personagem da novela "Terra Nostra". Essa mesma notícia pode ser considerada como uma representação do sucesso da mobilidade sócioeconômica, à medida que atribui aos engraxates o status de homens de negócio bem sucedidos.

Acredita-se que, também não por acaso, mas pela afinidade temática que unifica a programação para fortalecer os laços do sincretismo, na mesma semana, o Jor- nal Nacional exibiu uma série de matérias, relatando a disputa pela guarda do menino cubano, Elian. Aos seis anos de idade, Elian protagonizou, nos edições dos dias $10,12,14$ e 15 , um conflitante enredo noticioso, que envolvia, além de seus familiares, dois países ideologicamente antagônicos, Estados Unidos e Cuba.

No Brasil, acontecimentos em relação à guarda de crianças também foram noticiados pelo Jornal Nacional, na semana pesquisada. Em um gesto de solidariedade, na edição do dia 14 , pessoas anônimas tornaram-se padrinhos e madrinhas de crianças abandonadas, dedicando-lhes carinho e proteção.

O mesmo espírito protecionista em relação às crianças pareceu inspirar, no noticiário do dia 11, a prefeitura e organizações não governamentais do Recife, na criação do toque de recolher. Às 21 horas, todas as crianças que trabalhassem ou pedissem donativos seriam recolhidas $\mathrm{e}$ encaminhadas às suas respectivas famílias.

Outra notícia que evidenciou a figura infantil referia-se à enchente em São Paulo, divulgada nos dias 12 e 13. O menor Jackson transformou-se em herói ao proteger um bebê e sua irmã Talita, no teto de uma casa. Na edição do dia seguinte, o garoto reapareceu, chorando, em frente às câmeras ao lembrar-se dos momentos de desespero exibidos lentamente na edição do dia anterior.

Situações de violência contra crianças também foram mencionadas. A cantora mexicana Glória Trevi, acusada de abuso sexual contra menores, foi presa no Brasil. (Meses depois, Glória 
Trevi viria protagonizar uma história folhetinesca, que incluiu, entre outros ingredientes, uma misteriosa gravidez contraída dentro da carceragem da Polícia Federal, em Brasília).

Outra informação envolvendo essa faixa etária relatou que crianças, nos Estados Unidos, tinham aulas sobre assédio sexual como matéria escolar a fim de se defenderem de eventuais ataques.

Como extensão da problemática infantil, a exaltação dos valores juvenis ocupou parte significativa das tramas das duas telenovelas e do noticiário do Jornal Nacional. No período analisado, o vigor juvenil explicitou-se diariamente.

Nas duas novelas, encontravam-se jovens com diferentes características. A juventude de "Vila Madalena" se mostrou mais conservadora que a juventude de "Terra Nostra". Na primeira telenovela, os jovens conseguiam auto-afirmação através dos sonhos, do romantismo, do amor e dos planos para o futuro.

Era o caso dos personagens Nancy (Carla Marins) e Hugo (Thierry Figueira), que idealizavam seus planos e viviam uma história romântica, recheada de pureza e lirismo. Nancy, sonhadora, esperava encontrar o seu príncipe encantado. Hugo desejava ser um grande instrumentista para viver da música e assumir, através do casamento, uma vida ao lado de Nancy.

Em "Terra Nostra", os jovens se apresentavam menos conservadores e não manifestavam tantos pudores, principalmente os sexuais. Isso ficava mais evidente na personagem Angélica (Paloma Duarte), uma mulher jovem, extremamente avançada para a sua época. Administradora das fazendas do marido, Angélica mostrava que o jovem pode assumir responsabilidades.

A jovem Rosana (Carolina Kasting), no entanto, não vivia de sonhos. Seus anseios precisavam ser satisfeitos no momento em que se originavam. Dessa forma, Rosana não temia se entregar a amores momentâneos e, muito menos, desfrutar os prazeres do sexo. Rosana chegou ao ponto extremo de manter relações sexuais na casa do próprio pai sem temer represálias. Esse contraste era interessante, pois a novela que se passava nos fins do século XIX se mostrava mais atual que a que narrava fatos corriqueiros do ano 2000.

Os jovens de "Vila Madalena" viviam dilemas comuns à juventude brasileira: conflitos de personalidade, problemas existenciais, falta do diálogo na família. Os pais, frequentemente retratados como cada vez mais ocupados, com os problemas relacionados ao trabalho, davam pouca atenção aos filhos. Era o que acontecia com a personagem "Zu"- Zuleika (Fernanda Rodrigues), que sofria com a separação dos pais e com a solidão. Sua mãe Raquel (Luiza Tomé), administradora de um restaurante, dificilmente encontrava tempo para dialogar com a filha.

\section{Violência na grade da programação}

A semana em questão reservou boa parte do tempo de exibição das telenovelas à questão da violência. Armas brancas e de 
fogo, temas como a condenação de inocentes, violência nos presídios, críticas ao sistema penitenciário brasileiro fizeram parte dos capítulos de "Vila Madalena".

Solano (Edson Celulari), em um dos capítulos, recebeu das mãos dos outros presidiários, uma lista das leis definidas pelos internos. Em episódios exibidos nos dias 13 e 14 de janeiro de 2000, Solano escapa de uma agressão a golpes de estilete, perpetrada por um grupo de presos, comandados pelo personagem Xerife (Adalberto Nunes). Alertado a tempo por outro presidiário seu amigo, o homossexual Pink (Élcio Romar), Solano iludiu os seus desafetos ao colocar na cama onde pretensamente dormiria um boneco de pano.

Por ser outro fator relacionado à vida nos presídios, o homossexualismo foi descrito em cenas de "Vila Madalena", especialmente nas que mostraram a violência praticada contra os homossexuais. Em uma dessas cenas, Pink é espancado por Xerife e seus comparsas por avisar Solano de um atentado.

Em "Terra Nostra", as cenas mais marcantes de violência se passaram no capítulo exibido no dia 10 de janeiro de 2000, em que Francesco (Raul Cortez) narrava à Paola (Maria Fernanda Cândido) os motivos de sua imigração da Itália para o Brasil. Francesco envolvera-se em uma briga e, tentando se defender de um agressor que o ameaçava com uma faca, acabou por matá-lo.

O tema violência se sobressaiu no noticiário do Jornal $\mathrm{Na}$ cional, em várias situações: nas rodovias brasileiras, no comércio irregular de armas, no assédio sexual, em ações contra a fauna e a flora e através da guerra. 22,6 $\%$ do número de notícias veiculadas pelo telejornal nas edições estudadas mostraram alguma forma de violência.

As penitenciárias, espaço cênico mostrado em "Vila Madalena", se destacaram também no Jornal Nacional. No presídio de Piracicaba, no interior do Estado de São Paulo, 120 reféns viveram angustiantes 23 horas de tensão durante uma rebelião de detentos.

O ambiente do presídio reapareceu na notícia "Igreja nas Grades", onde presos que fundaram a Igreja Evangélica do Presídio Ary Franco, no Rio de Janeiro, deram testemunho do processo de conversão. Segundo a informação do $J N$, o projeto "Igreja nas Grades" propiciou a 320 seguidores várias mudanças positivas em suas vidas.

O telejornal também apresentou uma série de reportagens sobre a venda irregular de armas no Paraguai. Nos dias 10, 11, 13 e 17 , dez minutos do $J N$ denunciaram a venda ilegal de vários tipos de armas, inclusive uma caneta revólver, calibre 22, que mais parecia uma inovação criada nos filmes de agentes secretos.

\section{A sedução da mobilidade}

Uma das principais características da cultura de massa, segundo Edgar Morin, é a sua capacidade de mobilizar o lazer coletivo, através dos espetáculos, das competições, da televisão, do rádio, da leitura de jornais e revistas. "Não há dúvida de que mesmo com o jornal, o rádio, a televisão, o lar nunca 
foi tanto outro lugar" (MORIN, 1967, p. 74).

Thompson tem a mesma apreciação sobre o poder mobilizador da indústria cultural. Os meios de comunicação se tornam "um multiplicador da mobilidade", uma forma vicária de viajar que permite ao indivíduo se distanciar dos imediatos locais de sua vida diária" (THOMPSON, 1998, p. 185).

De todas as formas de mobilidade uma das que se destaca é a sócio-econômica. DeFleur e Ball-Rokleach enfatizam que "mobilidade virou meta comum", sobretudo pelos contos do escritor norte-americano Horatio Alger. Nessas narrativas, conhecidas como o mito de Horatio Alger, relata-se como um grande número de pessoas

Estavam determinadas a "subir trabalhando" - algo que não havia sido possivel nos sistemas mais rígidos das sociedades tradicionais. Nem todos "subiram", mas o sonho de fazê-lo foi amplamente compartilhado, e, de fato, a melhoria de status tornou-se necessária para evitar-se ser rotulado de um "fracasso". A emergente cultura urbano-industrial ressaltou o sucesso como princípio central dos estilos de vida e pensamento de milhões de individuos" (DEFLEUR E BALLROKLEACH: p. 201-202).

Em inúmeras obras de Alger, a trama gira em torno de uma mesma fórmula, na qual "um rapaz pobre, porém digno que começa a vida como jornaleiro ou engraxate, supera obstáculos impossíveis e atinge absoluto sucesso" (DEFLEUR E BALLROKLEACH, 1983, p. 201).
Além da modalidade sócioeconômica, a promessa de mobilidade se expressa em outros modos de transformações, sejam elas geográficas e até sexuais. O importante é que se passe a impressão de que tudo está sujeito a mudanças, principalmente quando elas significam alguma conquista para quem as alcança. Nas telenovelas analisadas foram múltiplos os exemplos de mobilidade.

\section{1) Mobilidade conjugal}

A troca de estado civil é um acontecimento corriqueiro. Os casais se separam e se casam com muita rapidez. Há ainda os concubinatos, frequentes na vida real e nas tramas ficcionais.

O caso mais evidente de mobilidade conjugal nas duas telenovelas aconteceu em "Terra Nostra". O sessentão Francesco (Raul Cortez) deixa a esposa Janete Magliano (Ângela Vieira) por uma relação amorosa com a jovem Paola (Maria Fernanda Cândido), que deixa o seu exparceiro, deputado Augusto Marcondes (Gabriel Braga Nunes).

Os personagens Rosana (Carolina Kasting), Giuliana (Ana Paula Arósio), Mateo (Thiago Lacerda) e Marco Antônio (Marcelo Anthony) passam quase toda a novela permutando parceiros.

Em "Vila Madalena", as relações amorosas vividas por Eugênia (Maitê Proença), Arthur (Herson Capri) e Solano (Edson Celulari) demonstram a facilidade com que se alteram as ligações conjugais. Pillar (Cristiana Oliveira), Solano (Edson Celulari) e Roberto (Marcos Winter) for- 
mam outro núcleo, enquanto as irmãs Bibiana (Yoná Magalhães) e Margot (Rosamaria Murtinho) e o personagem Franco (Francisco Cuoco) protagonizam um terceiro triângulo amoroso.

\section{2) Mobilidade geográfica e social}

Transitar de um lugar ao outro também foi uma ação marcante de mobilidade no enredo das telenovelas analisadas. Os meios de transporte, nas duas telenovelas, são instrumentos que viabilizam as mudanças. Esse tipo de mobilidade pôde ser facilmente identificado nos capítulos dos dias de 10 a 13, 15 e 17 de janeiro de 2000 .

O metrô de "Vila Madalena" serviu tanto para o deslocamento geográfico quanto como meio simbólico de ascensão social do subúrbio para as regiões da cidade mais bem dotadas de equipamentos urbanos. De fato, esses deslocamentos são comuns na teledramaturgia por simularem a possibilidade de promoção de uma classe considerada baixa economicamente para outra mais elevada.

Em "Terra Nostra", observou-se uma grande quantidade de tomadas dentro do trem, do coche, do bonde, das carruagens ou, até mesmo cenas em que os personagens aparecem montados em cavalos, representando a facilidade que se tem de se deslocar de um local ao outro.

\section{3) Mobilidade sócio-econômica}

Os exemplos de mobilidade mais visíveis que as duas telenovelas mostraram se referiram a casos de ascensão econômico-social no desenrolar das narrativas. Em todas as situações apresentadas, identificou-se uma clara conexão entre mobilidade, iniciativa privada e liberdade.

Em "Vila Madalena", a moto de Cachorro Louco (Marcelo Farias) é um símbolo do sucesso da livre iniciativa. Em "Terra Nostra", o coche doado por Francesco ao cocheiro da família, Damião (Gésio Amadeu), revela outro êxito de uma iniciativa privada. Damião passa a trabalhar sem patrões, fato que está diretamente ligado à promoção da liberdade.

Bartolo (Antônio Calloni), quando deixa o trabalho nas fazendas de Gumercindo (Antônio Fagundes) e parte para o interior de São Paulo para cultivar uvas, ganha do fazendeiro um cavalo e uma carroça - meios de transporte essenciais para a mobilidade na zona rural. Bartolo abandona o trabalho quase escravo a que eram submetidos os imigrantes italianos e torna-se dono do seu próprio negócio. A condição de construtores de sobrados em "Terra Nostra", realizada por Mateo (Thiago Lacerda) e seu parceiro italiano, Amadeo (Fábio Dias), explicita também uma iniciativa privada, de mobilidade e de liberdade.

Tão significativa quanto às outras situações de mobilidade foi a protagonizada por Paola no ambiente onde funcionará a sua emancipadora Fábrica de Macarrão.

Em "Vila Madalena", a iniciativa privada também é vista como fator de mobilidade. Pillar (Cristiana Oliveira) e Raquel (Luíza Tomé) administram negócios 
próprios. A primeira, uma pequena empresa que presta serviços de organização de festas infantis e a segunda, um restaurante.

\section{Mobilidade no jornal nacional}

O Jornal Nacional exibiu também exemplos de mobilidade, um deles quanto à liberdade sexual, em noticia sobre uma cidadã carioca, Rosemari da Costa, que discutiu com policiais na orla marítima do Rio de Janeiro pelo direito de fazer "topless".

Ainda no âmbito do comportamento sexual, outra matéria Os homossexuais na Grã-Bretanha ganharam o direito de servir às forças armadas - destacou a homossexualidade como uma escolha diferente da convencional.

As representações no campo da mobilidade econômica foram frequentes. Manifestaram-se em informações sobre o movimento das bolsas de valores, a respeito das possibilidades de se quitar uma dívida ou diretamente relacionadas a práticas do consumo: o uso de cartão de crédito como nova mania nacional e o crescente hábito de fazer compras via Internet.

Os ambulantes de temporada constituíram um exemplo de vida, exibido no final da edição do dia 12. Vendedores de Fortaleza, Vitória da Conquista, Brasília e do interior da Bahia circularam pelas praias cariocas no verão a fim de aumentar suas economias e espantar o desemprego.

Entretanto, a notícia mais emblemática da possibilidade de ascensão, articulada com a situação do personagem Tizil (André Gomes) da telenovela "Ter- ra Nostra" e o mito de Horatio Alger, foi relativa aos engraxates brasileiros que construíram uma carreira promissora em Nova Iorque. Com o sucesso empresarial, tornaram-se homens de negócio e garantiram conforto para suas famílias.

\section{Breves considerações}

$\mathrm{O}$ sincretismo da realidade e da ficção é um fenômeno universal. Na televisão brasileira, essa fusão do real e do imaginário se consolidou com mais intensidade no horário nobre da programação da emissora líder de audiência, Rede Globo. Há décadas milhões de brasileiros acompanham regularmente - para não dizer religiosamente - a sequência mais atraente de programas: novela das sete, Jornal Nacional - novela das nove.

Assegurar a fidelidade de uma audiência tão numerosa e heterogênea requer uma grande dose de dedicação, criatividade e talento. É preciso, todos os dias, manter a continuidade do espetáculo televisivo dentro de padrões técnicos e estéticos rigorosos. Essa operação envolve um meticuloso trabalho para prover a programação do equilíbrio adequado das porções de realidade e ficção, no trânsito entre as novelas e o jornalismo.

A proposta deste estudo foi descrever, com base em observações empíricas, como se dá um processo paralelo e complementar ao do sincretismo: a abordagem de temas comuns nas emissões jornalísticas e dramatúrgicas. Na análise qualitativa, identificamos o que pode- 
ria parecer mera coincidência: o noticiário e a novela tratando dos mesmos assuntos em perspectivas distintas. Infância maltratada, violência sem controle, a mobilidade como redenção libertadora.

Assim, poderíamos dizer que ao se referir enfaticamente a esses temas, o horário nobre da televisão não ignora os problemas sociais. Ao contrário, desnudaos. No entanto, não se esquece de transmitir uma mensagem de esperança ao indicar as possibilidades de transformação. Afinal de contas, nenhuma audiência suportaria o contato diário com tantas notícias terríveis se não recebesse ao menos um sinal de que as coisas podem melhorar. Ilusão, manipulação, alienação, alento. Cada telespectador lida com essas questões de acordo com suas convicções e experiências culturais.

\section{Referências}

ADORNO, Theodor; HOREKHEIMER, Max. Indústria Cultural: o Iluminismo como mistificação de massa. In: LIMA, Luís Costa (org.). Teoria da Cultura de Massa. 2. ed. Rio de Janeiro: Paz e Terra, 1978. p. 159-204

ARBEX, José. O poder da TV. São Paulo: Scipione, 1996.

ASCHER, Nélson. A realidade na tela de TV. Folha de S.Paulo, Cadernos de TV, p. 2. São Paulo, 15 de abril de 2001

BALOGH, Ana Maria. O discurso ficcional na TV. São Paulo: EDUSP, 2002

BARTHES, Roland. Crítica e Verdade. S. Paulo: Perspectiva/Fundo de Cultura, 1970.

BORELLI, Silva; PRIOLLI, Gabriel. A Deusa Ferida. Por que a Rede Globo não é mais a campeã absoluta de audiência. São Paulo, Summus Editorial, 2000.

BOURDIEU, Pierre. Sobre a Televisão. Rio de Janeiro: Jorge Zahar Editor, 1997.

BUCCI, Eugênio. Brasil em tempo de TV. São Paulo: Boitempo Editorial, 1996.

COUTINHO, Iluska. Telejornal e narrativa dramática: um olhar sobre a estrutura da informação em TV. In: PEREIRA JÙNIOR, Alfredo E. Vizeu; PORCELLO, Flávio Antônio Camargo; MOTA, Célia Ladeira. (Orgs.). Telejornalismo. A nova praça pública. Florianópolis: Insular, 2006 
DEBORD, Guy. A sociedade do espetáculo. Rio de Janeiro: Contraponto, 1997.

DEFLEUR, Melvin L. e BALL-ROKEACH, Sandra. Teorias da Comunicação de massa. Rio de Janeiro: Jorge Zahar, 1983.

DIAS, Wagner Teixeira; REZENDE, Guilherme Jorge de. (2003). O Sincretismo da realidade e da ficção na televisão brasileira: a construção do melodrama realista em Laços de Família(Rede Globo de Televisão). Vertentes, v. 21, p. 73-84. UFSJ, Jan./Jun. de 2003

ECO, Umberto. Tevê: a transparência perdida. In: Viagem na Irrealidade Cotidiana. Rio de Janeiro: Editora Nova Fronteira, 1984, pp. $182-204$

FAERMAN, Marcos. Ficção ou Realidade. Revista VOGUE 243: 78-85, março de 1998

HAGEN, SEAN. The mithe of perfection. The image of TV- Globo newscasters. Brazilian Journalism Research, v. 1, n. 2, Jul./dez. 2005. Brasília: Universidade de Brasília/Faculdade de Comunicação: Associação Brasileira de Pesquisadores em Jornalismo - SBPJor, 2005, p. 93-117, 2005

HAMBURGER, Esther. A construção da verossimilhança nas novelas. In: TRAVANCAS, Isabel; FARIAS, Patrícia (UFRGS.) Antropologia e Comunicação. Rio de Janeiro: Garamond, 2003, p. 125-148

HERZOG, Clarice; PIMENTA, Lyzia. Novela: um olhar sobre as influências e os modos de inserção da novela no cotidiano. Revista Mercado Global no 103. São Paulo. Rede Globo. $3^{\circ}$ Trimestre de 1997. p. 47-59

JESPERS, Jean-Jacques. Jornalismo Televisivo. Coimbra-Portugal: Minerva, 1998.

JOST, François. Seis lições sobre televisão. Porto Alegre: Sulina, 2004.

MARCONDES FILHO, Ciro. Televisão. São Paulo: Editora Scipione, 1994.

MARTIN- BARBERO, Jesus. Dos meios às mediações - Comunicação, cultura e hegemonia. Rio de Janeiro: Editora UFRJ, 1997.

MATTELART, Armand; MATTELART, Michèle. O Carnaval das imagens: a ficção na TV. São Paulo: Brasiliense, 1989. 
MEYER, Marlise. Folhetim- Uma história. São Paulo: Companhia das Letras, 1996.

MORIN, Edgar Cultura de Massa no Século XX- O Espírito do Tempo. Rio de Janeiro: Forense, 1967.

NEPOMUCENO, Rosa. Os Magos. Revista VOGUE, v. 243, p. 9497, mar. 1998.

SODRÉ, Muniz. Álbum de família. In: NOVAES, Adauto (org.). Rede Imaginária: Televisão e Democracia. São Paulo: Cia. das Letras/Secretaria Municipal de Cultura: 1991, p. 222-231.

TÁVOLA, Artur da. A Telenovela Brasileira - História, Análise e Conteúdo. São Paulo: Globo, 1996.

TEMER, Ana Carolina Rocha Pessoa; TONDATO, Márcia Perecín. A televisão em busca da interatividade - uma análise dos gêneros não-ficcionais. Brasília: Casa das Musas, 2009.

THOMPSON, John B. A mídia e a modernidade - Uma teoria social da mídia. 5.ed. Petrópolis: Vozes, 1998

Data do Recebimento: 15/05/2009

Data do Aceite: 24/06/2009 